\title{
Reseña de Actividad: “Acto de Homenaje y Entrega de Legajos Reparados de los/as Detenidos/as, Desaparecidos/as y Asesinados/as de la Facultad de Humanidades y Ciencias de la Educación"
}

\author{
Italo Ferretti \\ Facultad de Humanidades y Ciencias de la Educación - \\ Universidad Nacional de La Plata, Argentina \\ italoferretti94@gmail.com \\ Federico Ramirez \\ Facultad de Humanidades y Ciencias de la Educación - \\ Universidad Nacional de La Plata, Argentina \\ ramirez.federicog@gmail.com
}

Mayo de 2019, Ensenada

El pasado 27 de marzo se realizó en nuestra Facultad el Acto de Homenaje y Entrega de Legajos Reparados correspondientes a estudiantes, graduades, docentes y no docentes detenides-desaparecides y asesinades por el terrorismo de Estado. En el Polideportivo de la FaHCE, con una numerosa audiencia, participaron del acto autoridades de la Facultad y de la Universidad. El evento se enmarcó en un conjunto de políticas llevadas adelante por la Presidencia de la UNLP, tendientes a evidenciar el accionar represivo del Estado sobre la Universidad y, asimismo, mostrar las responsabilidades de las propias autoridades universitarias durante el período signado por el terrorismo estatal.

El acto fue organizado por la Prosecretaría de Derechos Humanos de la Facultad en conjunto con la Comisión de Memoria, Recuerdo y Compromiso, que toma su nombre del espacio que construyera la primera lista de desaparecides y asesinades de nuestra Facultad. De este modo, se observa la continuidad de las políticas de memoria a través de los años. La labor de aquella primera Comisión culminó en un acto el 20 de abril de 1995, cuando se colocó una placa en el edificio de la Facultad (en aquel entonces emplazado en calle 48 entre 6 y 7) con los nombres recuperados hasta aquel momento. Tales acciones conformaron una materialidad de la memoria que debía sostener los relatos sobre el pasado, ante un contexto de impunidad que amenazaba con el olvido. ${ }^{1}$ La placa fue trasladada en el año 2014 junto a la Facultad al predio del ex BIM III y se encuentra actualmente en el patio entre los edificios A y B.

La actual Comisión de Memoria, Recuerdo y Compromiso se constituye como un espacio donde participan todos los claustros de la Facultad, junto a representantes de los organismos de Derechos Humanos y de les familiares. Su propósito es trabajar en torno a la difícil tarea de habitar un predio que fue un Centro Clandestino de Detención, Tortura y Exterminio. En ese sentido, la Comisión interviene en la organización de las diversas actividades que dan cuenta del pasado del lugar: coordina así, junto a la Prosecretaría de Derechos Humanos, tareas propias de un sitio de memoria, como charlas, diversos actos y recorridos guiados por el espacio.

Ese miércoles 27, nuestro recorrido de llegada a la Facultad fue interrumpido en su rutina habitual por una innumerable cantidad de personas caminando por el patio, dirigiéndose hacia el Polideportivo. A lo largo del camino nos encontramos con los rostros de les compañeres desaparecides y asesinades, marcando el camino 
hacia el acto. Una vez llegados al edificio, nos hallamos entre un diverso público asistente, conformado por familiares, estudiantes, docentes y no docentes.

Apuntamos nuestro camino hacia las gradas, donde ya esperan el comienzo del acto varies de nuestres compañeres de estudio y trabajo, pero apenas cruzamos la entrada nos llama la atención cierta concentración al costado del salón. Dos muestras en circuito hacen de preludio al evento. La primera es un collage de emociones, condensadas en diferentes objetos personales de les compañeres preservados por las familias durante todos estos años: libros, apuntes, ropa y pertenencias de la infancia dispersos en pupitres antiguos, aquellos que debieron conocer tan bien durante su paso por las aulas. Llaman la atención algunos objetos que parecen deliberadamente posicionados para remarcar las ausencias: atriles vacíos, carteles que señalan valores y objetos que no aparecen, marcos de fotos sin su contenido. Si es parte del propósito de la muestra, es una figura potente.

Uno de los pupitres parece ser un paso obligado en el recorrido: los rostros, al ver su contenido, se quedan suspendidos, durante unos instantes parecen abstraerse de la multitud y el lugar. Nos acercamos y ante la imagen que encontramos no podemos evitar compartir la misma sensación: tenemos enfrente una pequeña remera y una bolsa bordada para llevar al jardín de infantes. ¿Por qué se produce una reacción tan unánime? Una primera impresión nos haría atribuirlo a la inocencia de une niñe. Sin embargo, consideramos que se trata más bien del testimonio de una ausencia, una trayectoria interrumpida por la violencia estatal, que de este modo atravesó también a familiares, compañeres, amigues, y aún hoy interpela a las nuevas generaciones y a la sociedad en general.

El recorrido por la muestra es muy lento, dado que el público no deja ningún pupitre sin observar. Cuando finalizamos nuestro propio recorrido nos encontramos con otra exposición, una muestra bibliográfica con un elocuente título: "La necesidad de las palabras". Se trata de un contrapunto entre el pasado y el presente: encontramos revistas editadas durante la época y varios libros, probable material de estudio de les compañeres desaparecides y asesinades. Pero también hay obras posteriores, de la colección de la Biblioteca de la Facultad, que abordan el accionar del Estado terrorista, la militancia y la radicalización políticas de los años 60 y 70 , entre otros temas.

La particularidad de esta muestra es que se encuentra organizada en dos sectores: cerca de la entrada se halla, junto a los objetos personales, la mayor cantidad de material bibliográfico. Además, del otro lado del salón, se propone un ejercicio de comparación sumamente interesante. Se exponen allí, bajo el título "Huellas de una época", programas de diversas asignaturas de la Facultad, contrastando sobre todo la conformación de las cátedras y los contenidos que se dictaban antes de 1975-1976 con aquellos de años posteriores. Este circuito finaliza con una serie de listas de nombres colgadas: son las boletas usadas en las elecciones del Centro de Estudiantes. Destacan los nombres de Franja Morada y el FAUDI, Frente de Agrupaciones Universitarias de Izquierda. De este modo, esta exposición doble nos acerca al universo al cual el acto pretende homenajear: les compañeres víctimas del terrorismo de Estado, en su esfera personal, pero también resaltando su pertenencia a la comunidad académica de la Facultad.

Es tanta la cantidad de público que llega y que recorre las muestras que el comienzo del acto se demora. En ese momento, las gradas del Polideportivo están totalmente ocupadas por trabajadores y estudiantes de la Facultad. Las sillas dispuestas para la ocasión se destinan a les familiares y amigues que recibirán los legajos reparados. Al costado del salón, colgada del pasillo de los baños en el entrepiso, hay una bandera. De color negro, destaca en blanco la habitual consigna: "Memoria, Verdad y Justicia. 30.000 presentes, ahora y siempre". Sobre un lado de la bandera, se ve dibujada una secuencia del pañuelo blanco de las Abuelas de Plaza de Mayo deviniendo en la paloma de la paz.

Mientras tanto, se reproduce en el fondo del escenario un video del descubrimiento en 1995 de la placa que recuerda a les desaparecides y asesinades de la Facultad. Le sucede un fragmento con el testimonio de Reyna Diez, primera Decana mujer de Humanidades, hablando de la Facultad durante su breve gestión entre 1973 y 1974. Sobre el final, el locutor oficial invita al público a tomar asiento varias veces y comienza el acto. Verónica 
Cruz, Prosecretaria de Derechos Humanos de la Universidad, da lectura a la resolución que establece la reparación de legajos en nuestra unidad académica y enmarca el acto en las políticas de Memoria, Verdad, Justicia y Reparación que la UNLP viene poniendo en práctica desde hace varios años. A continuación, la Decana de la Facultad, Ana Julia Ramírez, hace mención a las particularidades que tuvo la represión estatal en Humanidades: desde la gran cantidad de compañeres desaparecides y asesinades hasta el rol fundamental de la CNU antes del golpe de marzo de 1976. También rescata el compromiso que requiere habitar un predio como el del ex BIM 3 y celebra el trabajo llevado a cabo desde la Prosecretaría de Derechos Humanos de la Facultad y la Comisión de Memoria, Recuerdo y Compromiso. En este sentido, tratándose de una política que la Facultad viene promoviendo desde hace varias décadas, la Decana invita a sus predecesores a participar junto a ella y les representantes del Rectorado en la entrega de los legajos reparados.

Las autoridades bajan del escenario montado para la ocasión y comienza el reparto de legajos. El video que se estaba proyectando sobre el fondo del escenario cambia y pasa ahora a mostrar los rostros y nombres de cada une de les compañeres detenides-desaparecides y asesinades. A medida que el locutor menciona el nombre de cada compañere, sus familiares o amigues se acercan al escenario, donde alguna de las autoridades les entrega una copia del legajo en la que se indica su condición de desaparecide o asesinade por el terrorismo estatal.

Las primeras familias en recibir los legajos toman una actitud que constituirá una de las notas fuertes de la tarde: la imposibilidad de desprenderse del presente en esta reparación del pasado. Son constantes las críticas a los negacionismos que desde hace ya tiempo hostigan las políticas de memoria. Las consignas clásicas y unánimes que exclaman la presencia de les 30.000 compañeres y la demanda por Memoria, Verdad y Justicia son una voz de lucha en medio de un presente hostil. Son acompañadas por el público y repetidas por varias familias y amigues cuando recuperan los legajos de sus seres queridos. Asimismo, son numerosos los casos en los que reivindican los roles de militantes políticos de sus familiares, antes que su caracterización como meras víctimas del accionar represivo del Estado. Se destacan, sobre todo, las familias de les compañeres asesinades antes del comienzo de la dictadura, quienes señalan que la represión efectuada por la Triple A y la CNU también formó parte del terrorismo de Estado y expresan su rechazo a la impunidad de estos crímenes.

Entre quienes reciben los legajos reparados aparece una palabra común: gracias. Les que deciden hacer uso de la palabra manifiestan su agradecimiento por lo que entienden es una política de reparación por parte de la Universidad. Varios aspectos resultan interesantes: más allá del componente emotivo y conmovedor, las reacciones de les familiares están marcadas por la alegría al encontrar un lugar de acompañamiento ante su experiencia. Hay heridas difíciles o imposibles de cerrar, pero estos momentos les acercan más al recuerdo de sus seres queridos. Por esa razón, ni bien regresan a sus asientos, se apresuran a abrir las carpetas que les entregaron y dedican algunos minutos a hojear cada uno de los papeles que conforman el legajo.

Se visibilizan de esta manera y junto a las palabras que exponen, las diversas experiencias atravesadas por los círculos íntimos de les compañeres homenajeades. Las vivencias de les nietes restituides; las demandas y la militancia de les familiares por aquelles que faltan; les niñes que nunca fueron robades por los grupos de tareas, pero debieron crecer buscando conciliar la ausencia de sus padres. Muches hijes relacionan el acto de restauración con sus propias experiencias: conmueve la historia de una mujer que durante su juventud se había acercado a la Facultad para preguntar si había registros o algún elemento material que hiciera referencia al paso de su madre por la institución, ya que había crecido sin recuerdos materiales suyos. Y siempre, patente, la dificultad adicional de atravesar los contextos más hostiles de impunidad y olvido. Los discursos y actitudes tienen la marca de cuarenta años atravesados en medio del dolor y la ausencia.

El anuncio de cada nuevo legajo por parte del locutor es acompañado por una breve biografía de cada compañere desaparecide o asesinade. ${ }^{2}$ Allí se mezclan multitudes de experiencias vividas; diversas carreras de Humanidades, atravesadas por diferentes trayectorias militantes en organizaciones revolucionarias. En varios casos se trata de graduades de nuestras aulas que, posteriormente, se habían incorporado al plantel docente de la Facultad. Algunes de elles habían sido despedides o cesanteades antes de ser trasladades a los centros clandestinos de detención, tortura y exterminio. En muchos de estos casos, por la dificultad para 
contactar a familiares y amigues, recibieron los legajos reparados les delegades de Humanidades en ADULP y representantes de ATULP. Cuando estas mismas circunstancias se repetían en legajos de estudiantes eran entregados a miembros del Centro de Estudiantes de la Facultad.

Otra experiencia que queremos resaltar es la de les compañeres LGBT. Su persecución nos permite vislumbrar que, además de su componente ideológico y clasista, el genocidio llevado a cabo tuvo también un carácter patriarcal. En este sentido, la represión atravesó a su vez a las identidades disidentes. De esta manera, surgen nuevas reivindicaciones y debates gracias al contexto presente donde luchas que durante años fueron colocadas en una posición de subalternidad, hoy han alcanzado un lugar preponderante en el escenario político.

El público, que no disminuye pese a que el acto se ha extendido por varias horas, acompaña los momentos más movilizadores e interviene en la habitual exclamación de consignas, reivindicando la presencia de 30.000 compañeres detenides-desaparecides y resaltando el carácter genocida de la represión. Pero se ve profundamente conmovido ante la mención de tres nombres particulares: Rodolfo Walsh, Diana Teruggi y Laura Carlotto. Al momento del anuncio de sus nombres, los aplausos se tornan ensordecedores: se les celebra, tanto a elles como a sus familias, como figuras icónicas de la resistencia a la dictadura y la lucha por la memoria. Esos nombres condensan cuarenta años de reivindicaciones y militancia por los derechos humanos, pero también han sido considerados como símbolos de las luchas políticas de aquellos años.

Finalmente, destacamos el compromiso y acompañamiento de la comunidad académica de la Facultad en torno al acto, no sólo visible en la ya mencionada multitudinaria asistencia al evento, sino también en el camino hacia su realización. El acto fue difundido activamente por todos los claustros de la institución; las comisiones de estudiantes se abocaron a la tarea de reivindicar a sus compañeres por carrera armando muestras con las fotografías disponibles en diversos espacios del predio del ex BIM III, que una vez más es habitado y resignificado como espacio de memoria.

Diferentes impresiones quedan circulando al final de la jornada. Retornando por el camino del Polideportivo, vemos modificada la escena que nos había recibido horas antes. Los carteles con los rostros de les homenajeades, que habían sido una de las instantáneas del comienzo del día, son menos. Las familias recogían algunos del camino y se los llevaban, como un recuerdo adicional del acto. El camino de regreso, de esta manera, nos recuerda una vez más cómo la represión atravesó e implicó a las diferentes generaciones. Madres, padres, hermanes, amigues, hijes y ya incluso nietes marcados por una ausencia, un duelo con complejidades difíciles de sortear. Pero a la vez, la manera en que estas personas debieron procesar el dolor generó su compromiso y el de gran parte de la sociedad en torno a la tarea de recuperar la memoria, que también trasciende diversas generaciones hasta encontrar en jóvenes nacides y criades en democracia algunes de sus más fuertes y abocades militantes. Y fue para muches este compromiso el punto de partida hacia la defensa de los derechos humanos, tanto aquellos violentados durante las dictaduras militares y el terrorismo de Estado, como los que permanecen como deudas de la democracia. Quizás por esta razón haya sido más que apropiada la conclusión del acto, a cargo de la Orquesta Escuela de la UNLP, marcando la articulación generacional de los compromisos con la memoria, la verdad y la justicia.

\section{Notas}

1 Abbattista, L.; Casi, D.; Sampietro, V.; Stavale, M. (2017). Estudiar en el predio del ex BIM 3. Reflexiones sobre un proyecto de construcción de la memoria en la FAHCE-UNLP. Aletheia, 7 (14). En Memoria Académica. Disponible en: http://www.memoria.fahce.unlp.edu.ar/art_revistas/pr.7894/pr.7894.pdf

2 Algunos relatos biográficos de les detenides, desaparecides y asesinades de la Facultad de Humanidades y Ciencias de la Educación, junto con los casos conectados al CCDTyE del ex BIM III pueden encontrarse en Ramírez, M.J. y Merbilhaá, M. (Eds). (2015). Memorias del BIM: Biografías. Las víctimas de la Fuerza de Tareas 5 en La Plata, Berisso y Ensenada. La Plata: FaHCE-UNLP. El trabajo de recuperación histórica continuó y en 2018 se editó una nueva versión del libro, revisada y aumentada. Ambas versiones pueden encontrarse en el repositorio digital de la Biblioteca de la Facultad, 
Aletheia, vol. 9, n 18 , e018, junio-noviembre 2019, ISSN 1853-3701

Memoria Académica: http://www.memoria.fahce.unlp.edu.ar/libros/pm.373/pm.373.pdf y http://www.memoria.fah ce.unlp.edu.ar/libros/pm.695/pm.695.pdf 